\title{
Awareness, Knowledge, Attitude, and Practices in the Management of Biomedical Waste: A Multivariate Analysis of Associated Factors in Peruvian Students
}

\author{
Frank Mayta-Tovalino ${ }^{1}$, Arnaldo Munive-Degregori ${ }^{2}$, Rocío Bocanegra $^{3}$, Roman Mendoza ${ }^{4}$, Juan Alvitez ${ }^{5}$, Abigail Temoche $^{6}$
}

\begin{abstract}
Aim and objective: To evaluate the awareness, knowledge, attitude, and practices in the management of biomedical waste (BMW) by multivariate analysis of associated factors in Peruvian dentistry students.

Materials and methods: A cross-sectional, descriptive, analytical-multivariate study was conducted to evaluate the entire population of undergraduate dentistry students of the Universidad Nacional Mayor de San Marcos $(N=254)$ from April to October 2019. The variables analyzed were gender (X1), age (X2), year of study (X3), and marital status (X4). The Logit model was implemented including all risk factors to explain which variables significantly influence the dependent variable. The crude odd ratio (OR) was used with a level of significance $p<0.05$.

Results: The Logit model showed that age, gender, year of study and marital status do not significantly influence awareness, knowledge, attitude, and practices in the management of BMW, showing a crude OR of $1.095 \%$ confidence interval (Cl) $[0.89-1.14] ; 1.195 \% \mathrm{Cl}[0.68-2.02] ; 0.895 \%$ $\mathrm{Cl}[0.64-1.10]$ and $1.295 \% \mathrm{Cl}[0.37-3.93]$ respectively.

Conclusion: The variables age, gender, year of study and marital status do not significantly influence the awareness, knowledge, attitude, and practices in the management BMW of Peruvian dental students.

Clinical significance: This research allows to know the knowledge about the management of biomedical waste of Peruvian dental students. Keywords: Awareness, Biomedical waste, Dental student.

World Journal of Dentistry (2022): 10.5005/jp-journals-10015-1887
\end{abstract}

\section{INTRODUCTION}

Nonbiodegradable waste from gloves, gauze, plastic syringes, silicone, plasters, X-ray revealing liquid, among other products, is routinely produced during clinical activities in health centers, leading to the generation of environmental pollution. Such waste is commonly referred to as biomedical waste (BMW), although it is also known as clinical waste, medical waste and sanitary waste in different parts of the world. This type of waste constitutes approximately one third of the total waste generated in health centers. $^{1-3}$

Nonetheless, BMW can be even more dangerous since it can also contain infectious diseases/agents, which can cause soil, water and air pollution unless handled adequately. This usually occurs in hospitals, clinics, laboratories or the like during health care, research, tests or procedures related to humans or animals. For this reason, adequate management must be considered with regard to the handling of $\mathrm{BMW}$, including effective transport and waste elimination to avoid damage derived, and reusable materials should be recycled. ${ }^{2-4}$

In the last decades, the amount of BMW generated has significantly increased directly in proportion to the rise in the number of nonregulated dental offices which lack adequate BMW plans to manage the elimination of sharp materials, body tissues, fixing chemicals, mercury, silver thiosulfate, lead sheets, and amalgam, among other products. It is vital to address this public health problem. However, there is limited scientific literature on the attitude regarding BMW management among dental students, who are actually the future professionals who will be required to manage and protect the environment. ${ }^{5-8}$
${ }^{1}$ Postgraduate Department, CHANGE Research Working Group, Faculty of Health of Sciences, Universidad Cientifica del Sur, Lima, Peru

${ }^{2,3}$ Academic Department of Rehabilitative Stomatology, Faculty of Dentistry, Universidad Nacional Mayor de San Marcos, Lima, Peru

${ }^{4}$ Academic Department, Faculty of Dentistry, Universidad Nacional Federico Villarreal, Lima, Peru

${ }^{5,6}$ Academic Department, Faculty of Medicine, Universidad Nacional Federico Villarreal, Lima, Peru

Corresponding Author: Frank Mayta-Tovalino, Postgraduate Department, CHANGE Research Working Group, Faculty of Health of Sciences, Universidad Cientifica del Sur, Lima, Peru, Phone: +5112142500, e-mail: fmaytat@cientifica.edu.pe

How to cite this article: Mayta-Tovalino F, Munive-Degregori A, Bocanegra R, et al. Awareness, Knowledge, Attitude, and Practices in the Management of Biomedical Waste: A Multivariate Analysis of Associated Factors in Peruvian Students. World J Dent 2022;13(1):3-8.

Source of support: Nil

Conflict of interest: None

One clear example of BMW is solid and liquid waste from dental laboratories which are often disposed of without any sanitary control. The reasons for improper management are multiple: lack of supervision by health authorities, lack of knowledge and poor attitude of dental technicians as well as inadequate waste facilities. ${ }^{9,10}$

Currently, it is very important that students from the undergraduate level understand and become aware of the impact of the correct integral management of biomedical waste. Due to the potential effect and risk that these wastes can cause since they can cause cross-contamination among health personnel and a direct 
Table 1: Sociodemographic characteristics of Peruvian dentistry students

\begin{tabular}{lccc}
\hline Variable & Categories & $n$ & $\%$ \\
\hline Gender & Male & 100 & 39.3 \\
& Female & 154 & 60.6 \\
Year of study & Second & 57 & 22.4 \\
& Third & 75 & 29.5 \\
& Fourth & 66 & 25.9 \\
Marital status & Fifth & 56 & 22 \\
& Single & 250 & 98.4 \\
& Married & 0 & 0 \\
Age & Cohabiting & 4 & 1.5 \\
\hline
\end{tabular}

impact on the environment. Thus, the present study aimed to evaluate the awareness, knowledge, attitude and practices in the management of BMW by multivariate analysis of risk factors in Peruvian dentistry students.

\section{Materials and Methods Design and Sample Size}

The design of the present investigation was an observational, and analytical study. The unit of analysis was composed of undergraduate dentistry students. No probabilistic sampling was used because the entire population was evaluated. We evaluated all second to fifth-year students $(N=254)$ of the Faculty of Dentistry of the Universidad Nacional Mayor de San Marcos (UNMSM) Lima, Peru. During the academic year from September to December 2019. This investigation was carried out according to the Strengthening the Reporting of Observational Studies in Epidemiology (STROBE) guidelines.

\section{Inclusion criteria}

- Students of legal age and both sexes.

- Students duly enrolled during the 2019 academic year.

- Students providing informed consent.

- Students of preclinical and clinical courses.

\section{Exclusion criteria}

- Students with irregular enrollment.

- Students who did not wish to participate.

\section{Evaluation of Associated Factors}

The associated factors evaluated with respect to BMW management awareness, knowledge, attitude, and practices by predental students were: gender (X1), age (X2), year of study (X3), and marital status (X4), All these variables were established as they were the main co-variables that characterized the Peruvian dental students.

\section{Measuring Instrument}

A face-to-face survey was conducted where data collection was carried out with the help of the Biomedical Waste Management Awareness \& Knowledge (BWMAK) Questionnaire validated in a previous study. ${ }^{11}$ This instrument is composed of two parts. The first part contains questions focused on assessing the awareness of dentists regarding BMW incurred by dental care, and the second part contains questions about practices of dental care management among dentists. The BWMAK questionnaire has 13 questions of which the first three assess knowledge and attitude regarding management policies of BMW management, the following nine questions assess knowledge about BMW management practices, and the last questions assess the awareness of the subjects regarding the management of BMW. ${ }^{11}$ Finally, to avoid variations in the questions and answers of the original English questionnaire, the BWMAK was translated into Spanish by the Peruvian American Cultural Institute (ICPNA).

\section{Data Collection}

The students evaluated had no special training regarding the handling of BMW, only the clinical training of the pregraduate courses. All data collection was performed by a single observer, so no inter-examiner calibration was needed. Signed informed consent was obtained from all the study participants. Data were collected anonymously using the BWMAK instrument. A pilot study was previously carried out, and according to the information and feedback obtained, the questionnaire was modified. The participants of the pilot study were considered in all the individuals evaluated. Finally, each student filled out the self-administered questionnaire in approximately 15 minutes. All the data collection was performed by the same operator to avoid any bias in the collection of information.

\section{Statistical Analysis}

Descriptive analysis of the numerical variables was performed using arithmetic means and the standard deviation, while frequencies and percentages were obtained for the categorical variables. Bivariate analysis was performed using the Chi-square and Student's $t$-tests, as appropriate. Finally, logistic regression and odds ratio analyses were performed to determine the risk factors using the Logit models. The Stata ${ }^{\circledR} 15.0$ statistical software was used for the statistical analyses. A $p<0.05$ was considered statistically significant in all the analyses.

\section{Results}

Of the 254 students included, 154 were females (60.6\%), and the largest student population was in the third year of the study with 75 students (29.5\%). The marital status of being single was the most prevalent among the 254 students (98.4\%) evaluated and in relation to the average the mean age was $22.2 \pm 2.3$ years (Table 1).

The results were correlated according to gender because it is one of the most contrasted covariates in the antecedents. According 
Table 2: Student awareness of dental waste

\begin{tabular}{|c|c|c|c|c|c|}
\hline & \multicolumn{2}{|c|}{ Female } & \multicolumn{2}{|c|}{ Male } & \multirow[t]{2}{*}{$p$} \\
\hline & $n$ & $\%$ & $n$ & $\%$ & \\
\hline \multicolumn{6}{|c|}{ Q1. Awareness regarding different categories of biomedical waste generated in the clinic } \\
\hline Yes & 32 & 66.6 & 16 & 33.3 & 0.449 \\
\hline No & 122 & 59 & 84 & 40.9 & \\
\hline \multicolumn{6}{|c|}{ Q2. Awareness regarding various color coding for different types of biomedical wastes } \\
\hline Yes & 50 & 70.4 & 21 & 29.5 & 0.047 \\
\hline No & 104 & 56.8 & 79 & 43.1 & \\
\hline \multicolumn{6}{|c|}{ Q3. Human anatomical wastes should be disposed in } \\
\hline Yellow container & 28 & 52.8 & 25 & 47.1 & 0.494 \\
\hline Red container & 60 & 62.5 & 36 & 37.5 & \\
\hline Blue/white container & 6 & 60 & 4 & 40 & \\
\hline Black container & 21 & 53.8 & 18 & 46.1 & \\
\hline Don't know & 35 & 68.3 & 16 & 31.7 & \\
\hline No answer & 4 & 80 & 1 & 20 & \\
\hline \multicolumn{6}{|c|}{ Q4. Sharps should be disposed in } \\
\hline Yellow container & 47 & 54.6 & 39 & 45.3 & 0.004 \\
\hline Red container & 71 & 64.5 & 39 & 35.4 & \\
\hline Blue/white container & 2 & 16.6 & 10 & 83.3 & \\
\hline Black container & 30 & 73.1 & 11 & 26.8 & \\
\hline Don't know & 4 & 80 & 1 & 20 & \\
\hline No answer & 0 & 0 & 0 & 0 & \\
\hline \multicolumn{6}{|c|}{ Q5. Category of outdated or expired medicines fall in which category } \\
\hline Chemical waste & 30 & 69.7 & 13 & 30.2 & 0.024 \\
\hline Cytotoxic waste & 45 & 52.3 & 41 & 47.6 & \\
\hline Biotechnological waste & 50 & 56.1 & 39 & 43.8 & \\
\hline Don't know & 26 & 78.7 & 7 & 21.2 & \\
\hline No answer & 3 & 100 & 0 & 0 & \\
\hline \multicolumn{6}{|c|}{ Q6. Category of impression material and cotton } \\
\hline Solid waste & 64 & 70.3 & 27 & 29.6 & 0.04 \\
\hline Soiled waste & 89 & 54.9 & 73 & 45 & \\
\hline Infected waste & 1 & 100 & 0 & 0 & \\
\hline Don't know & 0 & 0 & 0 & 0 & \\
\hline No answer & 0 & 0 & 0 & 0 & \\
\hline
\end{tabular}

to awareness, there was no statistically significant association with the gender of the dentistry undergraduate students in relation to Q1 (Awareness regarding different categories of BMW generated in the clinic-0-Are you aware of the different categories of BMW generated in the clinic?) and Q2 (Awareness regarding various color codes for different types of BMW-o-Are you aware of the various color codes for different types of BMW ( $p>0.05)$. Finally, in relation to question Q4 (The sharp objects must be selected in?), Q5 (Category of expired or expired drugs in which?) and Q6 (Category of impression material and cotton) if there was a significant association according to sex (Table 2).

In relation to the attitudes and practices that undergraduate students have about dental waste management, only questions Q7 (Do you segregate different types of wastes in your clinic) and Q10 (How do you dispose of X-ray film lead foils and X-ray films) were significantly associated with gender $(p<0.05)$ (Table 3$)$.

This model showed that none of the independent variables (age, gender, year of study, and marital status) significantly influenced the awareness, knowledge, attitude, and practices in
BMW management. An adjusted logit model was not necessary because a crude odd ratio (OR) of 1.0 with a $95 \%$ confidence interval (Cl) was found [0.89-1.14]; $1.195 \% \mathrm{Cl}[0.68-2.02] ; 0.895 \% \mathrm{Cl}$ [0.64-1.10] and $1.295 \% \mathrm{Cl}[0.37-3.93]$ respectively (Table 4).

\section{Discussion}

This study was carried out to evaluate the awareness, knowledge, attitude, and practices in BMW management of Peruvian dental students and to determine the reality of waste management by public universities. Hospitals and other medical institutions have an obligation to preserve public health and must, therefore, take careful measures for disposing of BMW. Indeed, poor management of these waste products would put patients' health at risk. ${ }^{11-15}$

Dental care generates different types of potentially toxic waste, which may include solid or liquid products such as: gauze, gloves, masks, syringes, dental floss, dental impressions, wax, dental amalgam, among others, containing traces of saliva, blood and 
Table 3: Attitudes and practices of dental waste management

\begin{tabular}{|c|c|c|c|c|c|}
\hline & \multicolumn{2}{|c|}{ Female } & \multicolumn{2}{|c|}{ Male } & \multirow[t]{2}{*}{$p$} \\
\hline & $n$ & $\%$ & $n$ & $\%$ & \\
\hline \multicolumn{6}{|c|}{ Q7. Do you segregate different types of wastes in your clinic? } \\
\hline Yes & 64 & 70.3 & 27 & 29.6 & 0.040 \\
\hline No & 90 & 55.9 & 74 & 45 & \\
\hline \multicolumn{6}{|l|}{ Q8. How do you dispose of infected needles? } \\
\hline Dispose in common bin & 16 & 76.1 & 5 & 23.8 & \\
\hline Break the needle and dispose & 12 & 66.6 & 6 & 33.3 & 0.417 \\
\hline Destroy the needle in needle burner & 1 & 50 & 1 & 50 & \\
\hline Dispose of it in puncture proof bags & 125 & 58.6 & 88 & 41.3 & \\
\hline \multicolumn{6}{|l|}{ Q9. How do you dispose of developer and fixer? } \\
\hline Directly in the wash basin & 16 & 50 & 16 & 50 & \\
\hline Dilute it and dispose & 62 & 60.1 & 41 & 39.8 & \\
\hline Add new and reuse & 4 & 57.1 & 3 & 42.8 & 0.692 \\
\hline Others & 12 & 66.6 & 6 & 33.3 & \\
\hline Do not know & 60 & 63.8 & 34 & 36.1 & \\
\hline \multicolumn{6}{|c|}{ Q10. How do you dispose of X-ray film lead foils and $\mathrm{x}$ ray films? } \\
\hline Dispose in common bin & 46 & 49.4 & 47 & 50.5 & \\
\hline Store it separately and then dispose of in secured & 60 & 60 & 40 & 40 & \\
\hline Landfills by experts & 1 & 100 & 0 & 0 & 0.005 \\
\hline Bury it & 6 & 100 & 0 & 0 & \\
\hline Others & 41 & 75.9 & 13 & 24 & \\
\hline Do not know & 0 & 0 & 0 & 0 & \\
\hline \multicolumn{6}{|c|}{ Q11. How do you dispose of outdated or expired medicines? } \\
\hline Dispose in common bin & 61 & 59.2 & 42 & 40.7 & \\
\hline Store separately and dispose & 61 & 61 & 39 & 39 & \\
\hline Bury it & 2 & 100 & 0 & 0 & 0.821 \\
\hline Dispose it in secured landfills & 6 & 66.6 & 3 & 33.3 & \\
\hline Others & 24 & 60 & 16 & 40 & \\
\hline Do not know & 0 & 0 & 0 & 0 & \\
\hline \multicolumn{6}{|l|}{ Q12. How do you dispose of extracted teeth? } \\
\hline Dispose in common bin & 27 & 71 & 11 & 28.9 & \\
\hline Yellow container & 26 & 55.3 & 21 & 44.6 & \\
\hline Red container & 66 & 57.8 & 48 & 42.1 & \\
\hline Blue/white container & 11 & 68.7 & 5 & 31.2 & 0.667 \\
\hline Black container & 23 & 62.1 & 14 & 37.8 & \\
\hline \multicolumn{6}{|l|}{ Q13. How do you store excess silver amalgam? } \\
\hline Dispose in common bin & 27 & 71 & 11 & 28.9 & \\
\hline Store in air tight container with water & 26 & 55.3 & 21 & 44.6 & 0.667 \\
\hline Store in a fixer & 66 & 57.8 & 48 & 42.1 & \\
\hline Don't know & 11 & 68.7 & 5 & 31.2 & \\
\hline Do not use & 23 & 62.1 & 14 & 37.8 & \\
\hline
\end{tabular}

toxic agents which could be harmful to not only patients but also health care providers and even the environment. ${ }^{15,16}$

The present study found that an adequate proportion of Peruvian dental students knew about the management and practices of BMW and were aware of the need for adequate waste disposal protocols that are environmentally friendly. In addition, most of the students evaluated in the present study had an efficient attitude in relation to the management of BWM compared to studies carried out in other countries, ${ }^{15-17}$ thereby making the likelihood of these students becoming contaminated by BMW low. 
Table 4: Multivariate logistic regression model of each risk factor of awareness, knowledge, attitude and practices in the management of biomedical waste

\begin{tabular}{llcc}
\hline Independent variables & OR & $p$ & $95 \% \mathrm{Cl}$ \\
\hline (X1) Age & 1.0 & 0.869 & $0.89-1.14$ \\
(X2) Gender & 1.1 & 0.561 & $0.68-2.02$ \\
(X3) Year of study & 0.8 & 0.227 & $0.64-1.10$ \\
(X4) Marital status & 1.2 & 0.744 & $0.37-3.93$ \\
\hline
\end{tabular}

Logistic Model: All the variables were entered in the statistical analysis of the multivariate model

$\mathrm{Cl}$, Confidence interval; OR, Odds ratio

The Logistic model showed that age, gender, year of study and marital status do not significantly influence the awareness, knowledge, attitude, and practices in the management of biomedical waste

In the study by Bansal et al. ${ }^{11} 52 \%$ of the participants were men and $48 \%$ women. They found that only $14 \%$ of dentists were unaware of the types of waste categories in their health centers, and $12 \%$ of health personnel did not know the color-coding used for the waste disposal. In addition, around $26 \%$ had bad practices to eliminate sharp objects and freshly extracted teeth. Therefore, they concluded that most of the dentists evaluated in that study knew the categories and color codes used in the disposal of different types of waste, but they did not apply these protocols in their clinical practice. On the other hand, according to the study by Raghuvanshi et al. ${ }^{12} 80 \%$ of private practice dentists knew the BMW categories compared to $100 \%$ of public institution dentists. However, $41 \%$ of private dentists disposed of the chemical waste directly into sewers, and some private professionals disposed them directly without any treatment. They concluded that most dentists had adequate knowledge about the management of BMW. These results are similar to those of the present study which also found that a high percentage of Peruvian dentistry students (99.9\%) were aware of the color codes for different types of BMW.

However, our results differ from those of the study by Abhishek et al. ${ }^{13}$ including 186 professionals, 71 (38\%) of whom were women and 115 (62\%) were men. They found a significant association between the study subjects and their knowledge, practice, and management of dental waste. In addition, they reported a statistically significant correlation $(p=0.0001)$ between participants' knowledge and practice scores. They concluded that there was a poor level of knowledge about proper BMW disposal among the dentists in India evaluated. In contrast with our results, Sharma et al. ${ }^{14}$ found a low level of knowledge and awareness regarding risks, and BMW management among the health personnel evaluated. They also reported that $36 \%$ of nurses had extremely poor knowledge, and only $15 \%$ of health workers had excellent knowledge of the practice and management of BMW. Therefore, they concluded that there are low levels of knowledge and awareness about the risks, and management of BMW. These results are consistent with those described in the systematic review by Kapoor et al. ${ }^{15}$ which showed that the level of knowledge and awareness of the subjects evaluated in dental education institutions in India were inadequate in relation to the practice and the handling of BMW. Thus, BMW awareness programs are greatly needed to improve this situation.

Finally, contrary to the results of the present study, several other studies have also reported that not all dentists are aware of the risks to which they are exposed by bad BMW management, and only half of the participants in these studies observed infection control practices. Moreover, they are unaware of the proper management that should be taken regarding hospital waste. The lack of awareness about BMW among auxiliary dental staff in hospitals and dental clinics can generate multiple cross-contamination. ${ }^{16}$ Therefore, it is necessary to train health personnel about the risks associated with improper BMW disposal at all levels to ensure safety measures for the environment and public health. ${ }^{17}$

The main limitations of this research were the different study schedules to place students in the different courses they studied. Some students were not properly enrolled and could not sign the informed consent and were excluded from the study. Finally, data collection required the interruption of their class or clinical practice. However, one of the strengths of this study is that it allowed a situational diagnosis of how Peruvian public university dental students manage BMW. ${ }^{18}$ The results of this study demonstrate awareness of BMW management, effective recycling and the reuse of dental materials, which are necessary to prevent the exposure of teachers, students and administrative staff to risks. Nonetheless, further training and information are needed mainly in order to change attitudes.

According to the results of the present study, the following recommendations could be made: Continuous education on the management of BMW should be implemented by the Peruvian Ministry of Health. Faculty directors should enforce correct waste disposal or treatment according to the regulations of the Ministry of Health to avoid contamination to both the environment and persons in direct contact with BMW. Regulations and continuous evaluation of good BMW management protocols should be promoted among teachers, administrators and students to ensure awareness and good attitudes towards waste disposal in the appropriate containers.

\section{Conclusion}

In conclusion, within the limitations of the study the logit model showed that age, gender, year of study and marital status do not significantly influence the awareness, knowledge, attitude, and practices in the management BMW of Peruvian dental students.

\section{References}

1. Kumar R, Gupta AK, Aggarwal AK, et al. A descriptive study on evaluation of bio-medical waste management in a tertiary care public hospital of North India. J Environ Health Sci Eng 2014;12:69. DOI: 10.1186/2052-336X-12-69

2. Kumar PVS, Padmaja P. Knowledge, attitude, practices of biomedical waste management among nursing students and staff in a Tertiary Care Hospital. Ann Int Med Dent Res 2017;3(4):1-4. DOI:10.21276/aimdr.2017.3.4.CM1 
3. Singh BP, Khan SA, Agrawal N, et al. Current biomedical waste management practices and cross-infection control procedures of dentists in India. Int Dent J 2012;62(3):111-116. DOI: 10.1111/j.1875595X.2011.00100.x

4. Rudraswamy S, Sampath N, Doggalli N. Staff's attitude regarding hospital waste management in the dental college hospitals of Bangalore city, India. Indian J Occup Environ Med 2012;16:75-78. DOI: 10.4103/0019-5278.107077

5. Kishore J, Goel P, Sagar B, et al. Awareness about biomedical waste management and infection control among dentists of a teaching hospital in New Delhi, India. Indian J Dent Res 2000; 11: 157-161. PMID: 11307639.

6. Saraf $Y$, Shinde M, Tiwari SC. Study of attitude and awareness status about hospital waste management among personnel and quantification. Indian J Commun Med 2006;31:111. PMID: 14503385.

7. Haralur SB, Al-Qahtani AS, Al-Qarni MM, et al. The dental solid waste management in different categories of dental laboratories in Abha city, Saudi Arabia. Open Dent J 2015;9:449-454. DOI: 10.2174/1874210601509010449

8. Marla V, Agrawal D, Shrestha A, et al. Nepalese version of a questionnaire: biomedical waste management awareness and knowledge. Glob J Res Anal 2016;5(10):22-24. DOI: 10.36106/GJRA

9. Singh T, Ghimire TR, Agrawal SK. Awareness of biomedical waste management in dental students in different dental colleges in Nepal. Biomed Res Int 2018;2018:1742326. DOI: 10.1155/2018/1742326

10. Ranjan R, Pathak R, Singh DK, et al. Awareness about biomedical waste management and knowledge of effective recycling of dental materials among dental students. J Int Soc Prev Commun Dent 2016;6(5):474-479. DOI: 10.4103/2231-0762.192941

11. Bansal $M$, Vashisth $S$, Gupta N. Knowledge, awareness and practices of dental care waste management among private dental practitioners in Tricity (Chandigarh, Panchkula and Mohali). J Int Soc Prev Commun Dent 2013;3(2):72-76. DOI: 10.4103/2231-0762.122436

12. Raghuvanshi M, Sinha S, Mohiddin G, et al. Awareness of biomedical waste management among dentists associated with institutions and private practitioners of North India: a comparative study. J Contemp Dent Pract 2018;19(3):273-277. DOI: 10.5005/jp-journals-10024-2251

13. Abhishek KN, Supreetha S, Varma Penumatsa N, et al. Awareness-knowledge and practices of dental waste management among private practitioners. Kathmandu Univ Med J 2016;14(53):17-21. PMID: 27892435.

14. Sharma A, Sharma V, Sharma S, et al. Awareness of biomedical waste management among health care personnel in Jaipur, India. Oral Health Dent Manag 2013;12(1):32-40. PMID: 23474579.

15. Kapoor D, Nirola A, Kapoor V, et al. Knowledge and awareness regarding biomedical waste management in dental teaching institutions in India: a systematic review. J Clin Exp Dent 2014;6(4):e419-e424. DOI: 10.4317/jced.51565

16. Narang RS, Manchanda A, Singh S, et al. Awareness of biomedical waste management among dental professionals and auxiliary staff in Amritsar, India. Oral Health Dent Manag 2012;11(4):162-168. PMID: 23208592.

17. Sood AG, Sood A. Dental perspective on biomedical waste and mercury management: a knowledge, attitude, and practice survey. Indian J Dent Res 2011;22(3):371-375. DOI: 10.4103/0970-9290.87055

18. Diaz-Soriano A, Gallo W, Luza S, et al. Knowledge and awareness of effective recycling of dental materials and waste management among Peruvian undergraduate students of dentistry: a logistic regression analysis. J Int Soc Prev Commun Dent 2020;10(3):309315. DOI: 10.4103/jispcd.JISPCD_191_20 